in vivo $33: 1333-1339$ (2019)

doi:10.21873/invivo.11608

\title{
Grade 3 and 4 Toxicity Profiles During Therapy of Childhood Acute Lymphoblastic Leukemia
}

\author{
JOANNA ZAWITKOWSKA ${ }^{1}$, MONIKA LEJMAN ${ }^{2}$, AGNIESZKA ZAUCHA-PRAŻMO ${ }^{1}$, KATARZYNA DRABKO $^{1}$, \\ MARCIN PŁONOWSKI ${ }^{3}$, JOANNA BULSA ${ }^{4}$, MICHAŁ ROMISZEWSKI ${ }^{5}$, AGNIESZKA MIZIA-MALARZ ${ }^{6}$, \\ ANDRZEJ KOŁTAN ${ }^{7}$, KATARZYNA DERWICH ${ }^{8}$, GRAŻYNA KAROLCZYK ${ }^{9}$, TOMARZ OCIEPA $^{10}$, \\ MAGDALENA ĆWIKLIŃSKA ${ }^{11}$, JOANNA TRELIŃSKA ${ }^{12}$, JOANNA OWOC-LEMPACH ${ }^{13}$, \\ MACIEJ NIEDŹWIECKI ${ }^{14}$, ALEKSANDRA KIERMASZ ${ }^{15}$ and JERZY KOWALCZYK ${ }^{1}$ \\ ${ }^{1}$ Department of Pediatric Hematology, Oncology and Transplantology, Medical University of Lublin, Lublin, Poland; \\ ${ }^{2}$ Department of Pediatric Hematology, Oncology and Transplantology, \\ University Children's Hospital, Genetic Diagnostic Laboratory, Lublin, Poland; \\ ${ }^{3}$ Department of Pediatric Oncology, Hematology, Medical University of Białystok, Białystok, Poland; \\ ${ }^{4}$ Department of Pediatrics, Hematology and Oncology, Medical University of Zabrze, Zabrze, Poland; \\ ${ }^{5}$ Department of Hematology and Pediatrics, Children's Hospital, Warsaw, Poland; \\ ${ }^{6}$ Department of Pediatric Oncology, Hematology and Chemotherapy, Medical University of Katowice, Katowice, Poland; \\ ${ }^{7}$ Department of Pediatrics, Hematology and Oncology, Collegium Medicum of Bydgoszcz, Bydgoszcz, Poland; \\ ${ }^{8}$ Department of Pediatric Oncology, Hematology and Transplantology, Medical University of Poznań, Poznań, Poland; \\ ${ }^{9}$ Department of Pediatric Oncology and Hematology, Children's Hospital, Kielce, Poland; \\ ${ }^{10}$ Department of Pediatrics, Hematology and Oncology, Medical University of Szczecin, Szczecin, Poland; \\ ${ }^{11}$ Department of Pediatric Oncology and Hematology, Children's University Hospital, Kraków, Poland; \\ ${ }^{12}$ Department of Pediatrics, Oncology, Hematology and Diabetology, Medical University of Łódź, Łódź, Poland; \\ ${ }^{13}$ Department of Pediatric Transplantology, Oncology, Hematology, Medical University of Wrocław, Wrocław, Poland; \\ ${ }^{14}$ Department of Pediatrics, Hematology, Oncology and Endocrinology, Medical University of Gdańsk, Gdańsk, Poland; \\ ${ }^{15}$ Department of Pediatric Hematology and Oncology, Centre of Pediatrics and Oncology, Chorzów, Poland
}

\begin{abstract}
Background/Aim: The risk factors, clinical features and non-hematological toxicity profiles during chemotherapy in acute lymphoblastic leukemia (ALL) patients treated in pediatric hematology centres were analysed. Materials and Methods: A total of 902/1872 children were reported as having grade 3 or 4 toxicity. Results: Among the analysed toxicities, infection and gastrointestinal and liver toxicities were the most common. The median follow-up was 6.8 years. Overall survival and event-free survival rates for the analysed group were lower
\end{abstract}

This article is freely accessible online.

Correspondence to: Joanna Zawitkowska, MD, Ph.D., Department of Pediatric Hematology, Oncology and Transplantology, Medical University of Lublin, 6 Antoni Gębala Street, 20-093 Lublin, Poland. Tel: +48 507365635, e-mail: jzawitkowska1971@gmail.com, https://orcid.org/0000-0001-7207-156X

Key Words: Acute lymphoblastic leukemia, children, chemotherapy, toxicity. than those reported for the group without grade $\geq 3$ toxicity. In univariate analysis, we identified the number of toxic episodes, the risk group and remission status that had a significant impact on the outcome. Multivariate analysis demonstrated the risk group and the number of toxic episodes $\geq 3$ to be statistically significant for the results. Conclusion: The toxic profiles investigated in our report should be used in future efforts to decrease the burden of side effects during chemotherapy.

Over the last years, there has been an improvement in the overall survival of childhood acute lymphoblastic leukemia (ALL), which is now around $80-90 \%$. This is due to contemporary multidrug therapy regimens but, on the other hand, patients are burdened with severe complications of treatment $(1,2)$. Chemotherapy has a range of side-effects, such as infection, organ damage, hematological and other (malnutrition, hair loss). Most agents causing immunosuppression and myelosuppression increase the risk of bacterial, viral and fungal infections. The infection is still a major cause of death in ALL children $(3,4)$. Every organ may be adversely affected by anti-leukemic treatment, the most 
common complication being gastrointestinal toxicity, central and/or peripheral neuropathy, hepatotoxicity, nephrotoxicity, cardiac dysfunction, skeletal toxicity (4).

Toxicities may lead to deviations in chemotherapy, such as treatment delays, dose reductions or omissions. Literature data reveal that toxicity-induced therapy interruptions could also compromise treatment outcome. Thus, it is important to reduce toxicities in children with ALL. An analysis and discussion of side effects of therapy are necessary to establish strategies to minimize or abrogate them $(3,5)$.

In literature, there are limited data on the frequency of these complications in children with ALL and their impact on treatment outcome.

In this study, the risk factors, clinical features and nonhematologic toxicity profiles (grade 3 and 4) during chemotherapy in ALL patients treated in pediatric hematology centres in Poland were reported and analysed.

\section{Materials and Methods}

From October 2002 to December 2012 a total of 1872 children (813 females and 1059 males) were diagnosed with ALL and treated in 14 pediatric hematology centres in Poland (Polish Pediatric Leukemia and Lymphoma Study Group Report). Of those, 902 (48\%) were reported as having grade 3 or 4 toxicity. This study group included 383 females and 519 males, with a median age of 5.3 years (range $=1-18$ years).

The patients were treated according to ALL IC-BFM 2002 protocol, which was a randomized trial of the International Berlin-FrankfurtMunster Study Group (I-BFM-SG) for the therapy of childhood acute lymphoblastic leukemia, excluding Burkitt's leukemia. According to this protocol, the patients were classified into risk groups: standard (SRG), intermediate (IRG), and high-risk group (HRG). This depended on risk factors such as age, white blood cell count (WBC), response to steroids on day 8 , results of bone marrow evaluation on the 15 th or 33rd day of therapy, and presence of chromosomal abnormalities (fusion genes $B C R / A B L 1, K M T 2 A / A F 4$ ). Patients treated according to this protocol received induction of remission, consolidation, reinduction and maintenance therapy (6). The clinical and laboratory details of patients with ALL are presented in Table I.

The supportive therapy was administered according to the Polish Centers standards, although recommendations on supportive measures for the management and prevention of side effects of the cytostatic drugs were included in the treatment protocol. All patients during chemotherapy received anti-infective prophylaxis including oral cotrimoxazole $(25 / 5 \mathrm{mg} / \mathrm{kg} /$ day on 3 consecutive days/week) and oral fluconazole $(6 \mathrm{mg} / \mathrm{kg} / \mathrm{day})$ in the neutropenic phase. Use of recombinant human granulocyte colony-stimulating factor (rh-G-CSF; $5 \mathrm{mcg} / \mathrm{kg} /$ day subcutaneous injection) was mandatory for high - risk patients (after HR-blocks) and also oral posaconazole (weight $<34 \mathrm{~kg}: 18 \mathrm{mg} / \mathrm{kg} / \mathrm{day}$; weight $>34 \mathrm{~kg}$ or age $>13$ years: $600 \mathrm{mg} / \mathrm{day}$ ), if the patient was neutropenic. The prophylactic administration of oral acyclovir $(80 \mathrm{mg} / \mathrm{kg} /$ day $)$ was administered in children who were in contact with individuals sustaining varicella or zoster infection. Antiemetics were also standard. Organ function assessment was checked during chemotherapy (before start of each treatment phase). All patients in neutropenic phase received a low-bacterial diet and were treated with intensified hygiene measures (separate room). Toxicity profile during ALL IC-BFM 2002 was classified according
Table I. Clinical and laboratory details of ALL patients - comparison of children with and without toxicities grade 3-4.

\begin{tabular}{|c|c|c|c|}
\hline Patients & $\begin{array}{c}\text { Toxicity } 3-4 \\
n=902\end{array}$ & $\begin{array}{c}\text { Toxicity }<3 \\
\mathrm{n}=970\end{array}$ & $p$-Value \\
\hline Gender & & & 0.42 \\
\hline Female & $383(42.5 \%)$ & $430(44.3 \%)$ & \\
\hline Male & $519(57.5 \%)$ & $540(55.7 \%)$ & \\
\hline Median age/years (range) & $5.32(1-18)$ & $5.27(1-18)$ & 0.98 \\
\hline Infiltration CNS & $53(5.9 \%)$ & $61(6.3 \%)$ & 0.08 \\
\hline Testes & $9(1 \%)$ & $11(1.1 \%)$ & 0.77 \\
\hline Liver & $578(64.1 \%)$ & $629(64.8 \%)$ & 0.72 \\
\hline Mediastinum & $73(8.1 \%)$ & $58(6 \%)$ & 0.62 \\
\hline Spleen & $481(53.3 \%)$ & $456(47 \%)$ & 0.11 \\
\hline Risk group & & & 0.58 \\
\hline SRG & $292(32.4 \%)$ & $316(32.6 \%)$ & \\
\hline IRG & $430(47.7 \%)$ & $471(48.6 \%)$ & \\
\hline HRG & $180(20 \%)$ & $183(18.9 \%)$ & \\
\hline Immunophenotype & & & 0.14 \\
\hline \multicolumn{4}{|l|}{ Pre-B } \\
\hline Common positive & $502(55.7 \%)$ & $597(61.5 \%)$ & \\
\hline Common negative & $295(32.7 \%)$ & $283(29.2 \%)$ & \\
\hline T-ALL & $103(11.4 \%)$ & $107(11 \%)$ & \\
\hline AHL & $2(0.2 \%)$ & $1(0.1 \%)$ & \\
\hline \multicolumn{4}{|l|}{ Genetic aberration } \\
\hline $\begin{array}{l}\text { Karyotype with } \\
\text { aberration BCR/ABL1 }\end{array}$ & $43(4.8 \%)$ & $33(3.4 \%)$ & 0.12 \\
\hline \multicolumn{4}{|l|}{$\begin{array}{l}\text { Karyotype with } \\
\text { rearrangement }\end{array}$} \\
\hline KMT2A/AF4 (MLL) & $14(1.6 \%)$ & $18(1.9 \%)$ & 0.60 \\
\hline Prednisone response & & & 0.06 \\
\hline Good & $807(89.5 \%)$ & $839(86.5 \%)$ & \\
\hline Poor & $95(10.5 \%)$ & $131(13.5 \%)$ & \\
\hline Median $\%$ blast (BM) day 33 & & & 0.08 \\
\hline M1 & $879(97.5 \%)$ & $931(96 \%)$ & \\
\hline M2 & $16(1.8 \%)$ & $24(2.5 \%)$ & \\
\hline M3 & $7(0.8 \%)$ & $15(1.5 \%)$ & \\
\hline
\end{tabular}

SRG: Standard-risk group; IRG: intermediate-risk group; HRG: highrisk group; CNS: central nervous system; BM: bone marrow; M1 blasts $<5 \%$ blasts; $\mathrm{M} 2$ - blasts $\geq 5$ to $<25 \%$; M3 - blasts $\geq 25 \%$.

to the National Cancer Institute Common Toxicity Criteria (NCI CTC) version 2.0 (7), modified by GPOH (the German Society of Pediatric Oncology and Hematology). Definitions of grade 3 and 4 toxicities are presented in Table II.

Statistical analysis was performed with STATISTICA 12.0 software. Non-parametric tests such as Mann-Whitney $U$ and Kruskal-Wallis were applied to perform univariate analysis. Survival curves were estimated according to the Kaplan-Meier method and compared by the log-rank test. Multivariate analysis was performed with Cox Model (Hazard Ratio) and $p<0.05$ was considered statistically significant.

\section{Results}

A total of 3,190 toxic episodes were reported. Complications occurred in the induction phase of therapy in $36.58 \%$ of cases, in the consolidation phase in $10.47 \%$, in high-risk 
Table II. Description of toxicity grades in the analyzed group of ALL patients based on NCI CTC version 2.0, modified by GPOH.

\begin{tabular}{|c|c|c|}
\hline & Grade 3 & Grade 4 \\
\hline General condition & Bedridden, in need for nursing & Intensive care, very sick \\
\hline \multicolumn{3}{|l|}{ Infection } \\
\hline Infection & Pathogen identified, IV antibiotics & Septic shock \\
\hline Fever $\left({ }^{\circ} \mathrm{C}\right)$ & $>40<24 \mathrm{~h}$ & $>40 \geq 24 \mathrm{~h}$ \\
\hline \multicolumn{3}{|l|}{ Gastrointestinal toxicity } \\
\hline Nausea & Almost no food intake & TPN necessary \\
\hline Vomiting (in $24 \mathrm{~h}$ ) & $6-10$ & $>10 /$ TPN necessary \\
\hline Stomatitis & Painful ulceration, cannot eat & TPN required due to stomatitis \\
\hline Diarrhoea (stool frequency/day) & $7-9$ or incontinence or strong cramps & 10 or bloody diarrhoea or TPN required \\
\hline \multicolumn{3}{|l|}{ Liver toxicity } \\
\hline S-bilirubin & $>3.0-10.0 \times \mathrm{N}$ & $>10.0 \times \mathrm{N}$ \\
\hline S-ALT/S-AST & $>5.0-20.0 \times \mathrm{N}$ & $>20.0 \times \mathrm{N}$ \\
\hline \multicolumn{3}{|l|}{ Renal toxicity } \\
\hline Creatinine & $>3.0-6.0 \times \mathrm{N}$ & $>6.0 \times \mathrm{N}$ \\
\hline Proteinuria $(\mathrm{g} / \mathrm{l})$ & $>10.0$ & Nephrotic syndrome \\
\hline Hematuria & Macroscopic with clots & Transfusion required \\
\hline Creatinine clearance $\left(\mathrm{ml} / \mathrm{min} / 1.73 \mathrm{~m}^{2}\right)$ & $20-39$ & $\leq 19$ \\
\hline \multicolumn{3}{|l|}{ Cardiac toxicity } \\
\hline Arrhythmia & Therapy required & $\begin{array}{c}\text { Hypotension, ventricular arrhythmia, } \\
\text { defibrillation }\end{array}$ \\
\hline Cardiac function & $\begin{array}{l}\text { Mild cardiac insufficiency, therapeutically } \\
\text { compensated }\end{array}$ & $\begin{array}{c}\text { Severe/refractory } \\
\text { cardiac insufficiency }\end{array}$ \\
\hline Echo-CG: LV-SF & $>15 \%-<20 \%$ & $\leq 15 \%$ \\
\hline \multicolumn{3}{|l|}{ Neurologic toxicity } \\
\hline Central neurotoxicity & $\begin{array}{l}\text { Somnolence } \geq 50 \% \text { of the day, } \\
\text { disorientation, hallucinations }\end{array}$ & Coma, seizures \\
\hline Peripheral neurotoxicity, Myopathy & Unbearable paresthesia, marked motor deficits & Paralysis \\
\hline \multicolumn{3}{|l|}{ Skeletal toxicity } \\
\hline Osteonecrosis & Symptomatic and restrictions in everyday living & Symptomatic, crippling \\
\hline
\end{tabular}

$\mathrm{N}$ : Normal for age; LV-SF: left-ventricle shortening fraction; IV: intravenous; TPN: total parenteral nutrition.

(HR) blocks in $20.31 \%$, and in the reinduction phase in $32.63 \%$ of episodes. Grade 3 toxicities were more frequent $(77.5 \%)$ than grade $4(22.5 \%)$. The general condition was evaluated as grade 3 or 4 in 298 patients, which accounted for $12.2 \%$ of the incidents. Among the analysed toxicities in children with ALL, the most common included infection, gastrointestinal toxicity and hepatotoxicity. In our study 1,067 infective episodes $(32.3 \%)$ occurred in 537 children, $934(28.2 \%)$ events of hepatotoxicity were reported in 527 patients and $675(20.4 \%)$ cases of gastrointestinal toxicities in 346 children. Cardiac toxicities were observed in 50 patients $(2.7 \%$ episodes) and neurologic in $69(2.9 \%)$. The episodes of renal and skeletal toxicities ranged below $1.5 \%$. The number of events in the study group is presented in Figure 1.

In the study group, 135 (15\%) patients died (SRG - 14 pts, IRG - 56, HRG - 65). A relapse was diagnosed in 120 $(13 \%)$ patients (SRG - 26 pts, IRG - 60, HRG - 34) and 66 of those children died. A total of $69 / 1872$ patients died due to toxicity, so the non-relapse toxic mortality was $3.7 \%$. The median follow-up was 6.8 years (range $=0.05-13$ years). The 5-year overall survival (OS) and event-free survival (EFS) rates of the analysed group were 0.85 and 0.79 , respectively, and in the group without toxicity grade $\geq 3$ were 0.87 and 0.8 ( $p=0.89 ; p=0.78)$, respectively. OS and EFS of ALL patients are presented in Figure 2.

No differences were found in terms of clinical features of patients with and without grade 3 and 4 toxicity at the time of diagnosis. Therefore, we decided to include into the univariate and multivariate analyses only factors related to treatment intensity (the number of toxic episodes, the risk group, remission status). The number of toxic episodes ranged from 1 to 24 , with a median of 3 . In univariate analysis, three factors were identified in patients with ALL who experienced grade 3 or 4 toxicity that had a significant impact on the outcome. They are presented in Table III. In multivariate analysis, two factors (the risk group, the number of toxic episodes) were found to be statistically significantly associated with the results of treatment (Table IV). 


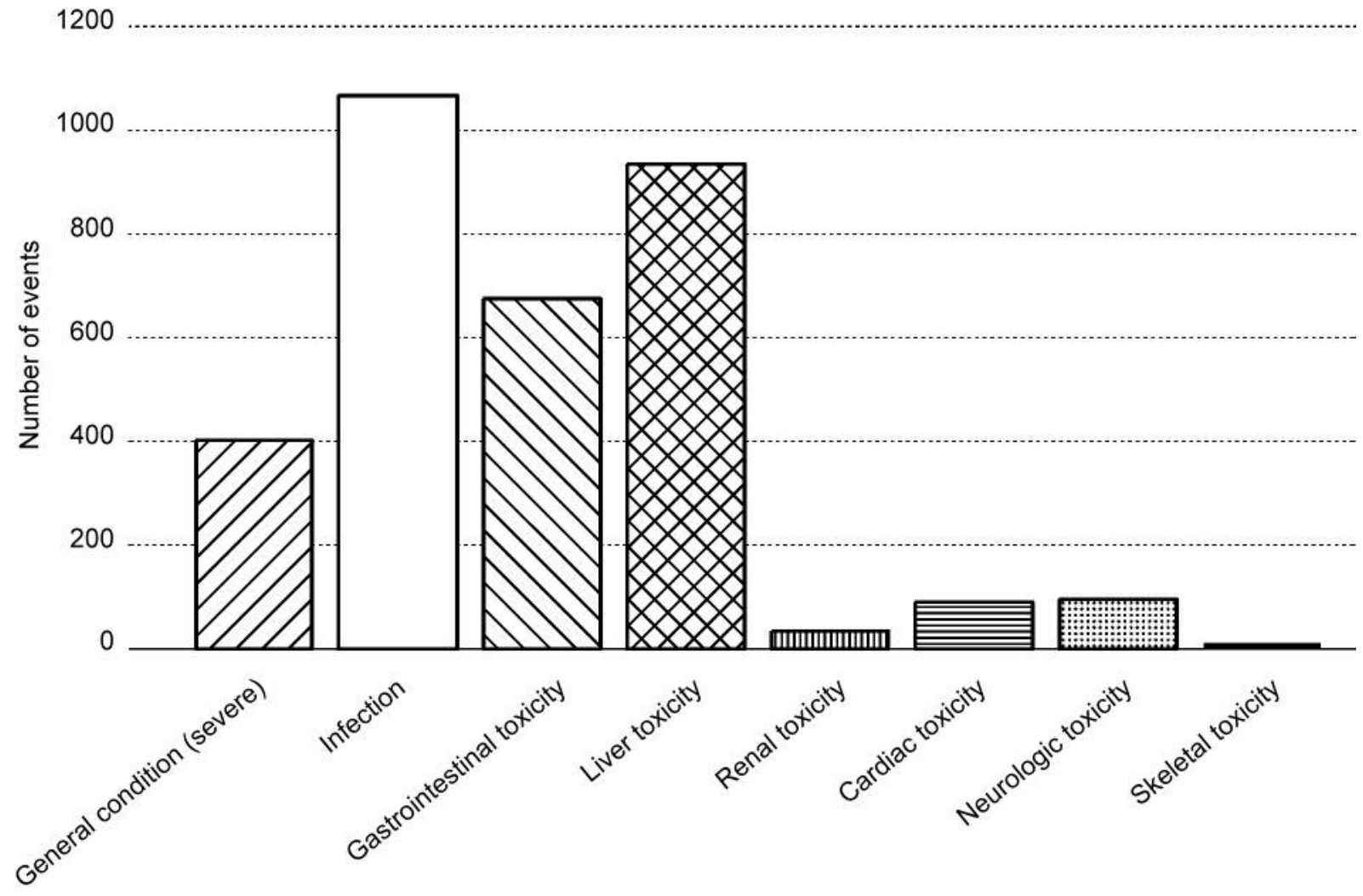

Figure 1. The number of grade 3 and 4 toxic events in all the studied group.

\section{Discussion}

Therapy-related complications reduce the cure rate of childhood acute lymphoblastic leukemia with $2 \%$ to $3 \%$ of deaths as a result of toxicity (6). In our study, the non-relapse toxic mortality was high. This may result from a long period of analysis and changing standards of supportive therapy. Nearly all children experience stomatitis and serious infections, and although various other severe, acute toxicities have a relatively low incidence individually, around $50 \%$ of all patients will be affected by at least one of these (4).

Stary et al. (6) reported on a large, intercontinental study of the incidence of common grade 3 and 4 non-hematologic toxicities for all risk groups, from 2002 to 2007. In that study, as in our analysis, there were more cases of infection, liver damage, gastrointestinal toxicity and a poor general condition of patients. These complications appeared predominantly in the HR group.

Lund $e$ al. (8) investigated the pattern of treatment-related deaths (TRDs) and possible risk factors in the NOPHO ALL92 and ALL-2000 protocols. Infections were the major cause of death comprising $72 \%$ of all cases. Other causes of death included bleeding or thrombosis, tumour burden related
Table III. The univariate analysis of factors influencing survival in patients with ALL who experienced grade 3 or 4 toxicities.

$\begin{array}{ccc}\text { 5-year } & p \text {-Value } & 5 \text {-year } \\ \text { OS } & \text { EFS } & \end{array}$

\begin{tabular}{lllll}
\hline Remission status & & & & \\
$\quad$ Remission day 33, $\mathrm{n}=879$ & 0.86 & $<0.0001$ & 0.80 & 0.0002 \\
$\quad$ Non-remission day 33, $\mathrm{n}=23$ & 0.52 & & 0.48 & \\
Number of toxic episodes & & & & \\
1-2 toxic episodes, $\mathrm{n}=437$ & 0.89 & 0.0001 & 0.83 & 0.0006 \\
$\quad \geq 3$ toxic episodes, $\mathrm{n}=465$ & 0.80 & & 0.75 & \\
Risk group & & & & \\
$\quad$ SR, $\mathrm{n}=292$ & 0.95 & $<0.0001$ & 0.89 & $<0.0001$ \\
IR, $\mathrm{n}=430$ & 0.87 & & 0.80 & \\
HR, $\mathrm{n}=180$ & 0.63 & & 0.59 & \\
\end{tabular}

OS: Overall survival; EFS: event-free survival; SR: standard- risk; IR: intermediate-risk; HR: high-risk.

toxicities and organ toxicity. Female gender, white blood cell count at diagnosis, T-cell disease, Down syndrome, and hematopoietic stem cell transplantation in CR1 were identified as independent risk factors for TRD. 

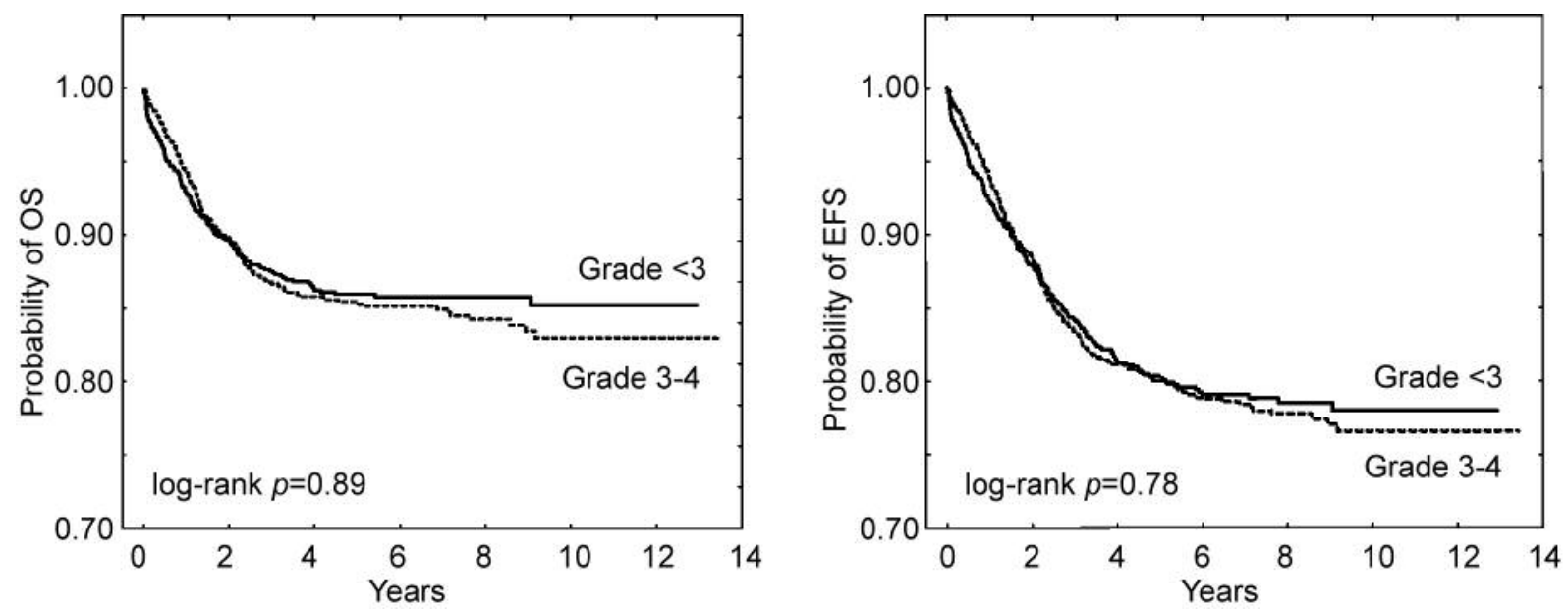

Figure 2. Overall survival (OS) and event-free survival (EFS) in ALL patients with and without toxicity grade 3-4.

Table IV. The multivariate analysis of factors influencing OS and EFS rates in patients with ALL who experienced grade 3 and 4 toxicities.

\begin{tabular}{|c|c|c|c|c|}
\hline \multirow[b]{2}{*}{ Factor } & \multicolumn{2}{|c|}{ 5-year OS } & \multicolumn{2}{|c|}{ 5-year EFS } \\
\hline & HRG & $p$-Value & HRG & $p$-Value \\
\hline$\geq 3$ toxic episodes $v s$. less than 3 & $1.1(1.08-1.2)$ & 0.02 & $1.06(1.02-1.1)$ & 0.03 \\
\hline HRG vs. SRG or IRG & $2.2(1.7-2.7)$ & 0.0001 & $1.8(1.5-2.3)$ & 0.0001 \\
\hline
\end{tabular}

OS: Overall survival; EFS: event-free survival; SRG: standard-risk group; IRG: intermediate-risk group; HRG: high-risk group.

Li et al. (9) retrospectively reviewed fever events during chemotherapy in 252 patients. Fever occurred in 219 patients $(86.9 \%)$ with a mean of 2.74 episodes per person. The fever events comprised $64 \%$ of febrile neutropenia, $39 \%$ clinically documented infections, and $44 \%$ of microbiologically documented infections. Infections developed primarily during the induction phase, where the risk factors included a younger age and a higher risk posed by the treatment regimen.

In our study group $32.3 \%$ of infections were reported in 537 (59.5\%) ALL children, which occurred mainly during the induction and reinduction of leukemia therapy. In our research, we found factors, such as remission status, number of toxic events grade 3 or 4 , and risk groups, which influenced the results of treatment. A worse outcome may not only result from the risk group status, but may also be the effect of the type and number of toxicities.

Hepatotoxicity is a common treatment-related toxicity (TRT) during contemporary treatment regimens for ALL. Denton et al . (10) identified 262 patients, of whom 71 (27\%) developed hepatotoxicity. Approximately $25 \%$ of hepatotoxicities (18/71) occurred during induction alone. Canbolat et al. (11) documented 279 acute complications other than febrile neutropenia episodes occurring between 2009-2014. Of those, therapy-related hepatitis was observed in $15.6 \%$ of children. Side effects occurred in $32.62 \%$ of cases during the induction phase, in $19.35 \%$ during the consolidation phase, in $18.28 \%$ in HR blocks, and in $29.75 \%$ during treatment reinduction. In our study, 934 episodes $(20.4 \%)$ of hepatotoxicity were reported mainly during the induction and reinduction phases.

Gastrointestinal mucositis disrupts the intestinal immunological barrier and is a risk factor for systemic infections (4). Inaba et al. (12) evaluated infection-related complications that were grade $\geq 3$ in 409 children. Of the 2420 infection episodes, gastrointestinal tract infections were seen in 145 patients. Those episodes were more common during intensified therapy phases, such as remission, induction and reinduction. Our results present 675 (20.4\%) episodes of grade 3 and 4 gastrointestinal toxicity in 346 patients with ALL, which occurred during the reinduction phase and HR blocks. 
Literature data show that central nervous system (CNS) toxicities during chemotherapy are infrequent adverse events and occur in 10-15\% of patients with childhood ALL (4). Millan et al. (1) published a retrospective analysis of 1379 ALL cases. Neurotoxicity was diagnosed in 49 patients (3.6\%) and occurred during the induction phase in $55 \%$ of cases.

Baytan et al. (13) retrospectively analysed the hospital reports of 323 children with de novo acute lymphoblastic leukemia from a 13-year period of acute neurological complications. Twenty-three of 323 children (7.1\%) suffered from CNS complications during acute lymphoblastic leukemia treatment. The majority of these complications developed during the induction period.

Peripheral (motor, sensory) neuropathies are common, usually caused by vincristine, and are basically completely reversible, but may require many months to improve (4). The study published by Nazir (14) reported that 19 out of 103 pediatric patients developed VCR-related neuropathy. Clinical symptoms started after 2-11 doses of VCR.

Our study demonstrated that neurotoxic events (peripheral and CNS) were not frequent (95 episodes/ 69 children) and observed during induction and subsequent reinduction phases of chemotherapy.

The most severe skeletal complication is symptomatic ON, caused by bone death resulting from poor blood supply. Biddeci et al. (15) evaluated 495 children and young adolescents with a diagnosis of ALL between 2000 and 2017. A total of $234.6 \%) / 495$ patients presented ON. Osteonecrosis was associated with an older age $(p<0.0001)$ and a higher steroid dose $(p=0.0013)$.

In our study, the 5-year OS and EFS rates in the group of children with toxic events $>$ grade 2 and <grade 3 were compared. Both OS and EFS in patients with grade 3 and 4 toxic episodes were shorter, but the differences were not statistically significant.

In conclusion, the toxic profiles presented in our report should be used in future efforts to decrease the burden of side effects during chemotherapy. The main emphasis should be placed on supportive care and monitoring of toxic events. Our study, similarly to literature data, indicated that complications occurred more often in the induction and reinduction phases of therapy. The toxic episodes mainly relied to infections, hepatotoxicity and gastrointestinal toxicity.

By analysing literature data, certain genetic factors could be important regarding the reduction of toxicity incidence in children in a similar way as the identification of a subset of patients with a higher risk for toxicities. New strategies as well as personalizing therapies in the case of toxicity could help improve survival, especially after many toxic episodes. The progress, which has been made in recent years in genetic diagnostics, has caused a genetic division among patients with the diagnosis of ALL. Currently, FCM-MRD (flow cytometry minimal residual disease) and PCR-MRD (polymerase chain reaction minimal residual disease) have become the most important tools in the treatment protocol. Additionally, gene rearrangements will be studied for ALL patients, such as ETV6-RUNX1, which have not been analyzed to date but will directly reduce the toxicity risk (16). All authors underline the importance of the cooperation of many specialists in the care of children with acute toxicities.

\section{Conflicts of Interest}

There are no conflicts of interest regarding this study.

\section{Authors' Contributions}

JZ, ML planned the study and were responsible for the study design. AZP, KD, MP, JB, MR, AMM, AK, KD, GK, TO, MĆ, JT, JOL, $\mathrm{MN}, \mathrm{AK}$ collected the clinical data. JZ, ML, AZP, KD, JK analysed and interpreted the data, wrote, and supervised the paper. All Authors read and approved the final manuscript.

\section{Acknowledgements}

This research did not receive any specific grant from funding agencies in the public, commercial, or not-for-profit sectors.

\section{References}

1 Millan NC, Pastrana A, Guitter MR, Zubizarreta PA, Monges MS and Felice MS: Acute and sub-acute neurological toxicity in children treated for acute lymphoblastic leukemia. Leuk Res 65: 86-93, 2018. PMID: 29328996. DOI: 10.1016/j.leukres. 2017.12.010

2 Wolthers BO, Frandsen TL, Baruchel A, Attarbaschi A, Barzilai S, Colombini A, Escherich G,Grell K, Inaba H, Kovacs G, Liang DC, Mateos M, Mondelaers V, Moricke A, Ociepa T,Samarasinghe S, Silverman LB, van der Sluis IM, Stanulla M, Vrooman LM, Yano M,Zapotocka E, Schmiegelow K and Ponte di Legno Toxicity Working G: Asparaginaseassociated pancreatitis in childhood acute lymphoblastic leukaemia: An observational pontedi legno toxicity working group study. Lancet Oncol 18(9): 1238-1248, 2017. PMID: 28736188. DOI: 10.1016/ S1470-2045(17)30424-2

3 Yeoh A, Collins A, Fox K, Shields S, Ritchie P, Kirby M and Revesz T: Treatment delay and the risk of relapse in pediatric acute lymphoblastic leukemia. Pediatr Hematol Oncol 34(1): 38-42, 2017. PMID: 28287326. DOI: 10.1080/08880018. 2016. 1276235

4 Schmiegelow K, Muller K, Mogensen SS, Mogensen PR, Wolthers BO, Stoltze UK, Tuckuviene R and Frandsen T: Noninfectious chemotherapy-associated acute toxicities during childhood acute lymphoblastic leukemia therapy. F1000Res 6: 444, 2017. PMID: 28413626. DOI: 10.12688/f1000research. 10768.1

5 Hough R and Vora A: Crisis management in the treatment of childhood acute lymphoblastic leukemia: Putting right what can go wrong (emergency complications of disease and treatment). Hematology Am Soc Hematol Educ Program 2017(1): 251-258, 2017. PMID: 29222263. DOI: 10.1182/asheducation-2017.1.251 
6 Stary J, Zimmermann M, Campbell M, Castillo L, Dibar E, Donska S, Gonzalez A, Izraeli S, Janic D, Jazbec J, Konja J, Kaiserova E, Kowalczyk J, Kovacs G, Li CK, Magyarosy E, Popa A, Stark B, Jabali Y, Trka J, Hrusak O, Riehm H, Masera $\mathrm{G}$ and Schrappe M: Intensive chemotherapy for childhood acute lymphoblastic leukemia: Results of the randomized intercontinental trial all ic-bfm 2002. J Clin Oncol 32(3): 174184, 2014. PMID: 24344215. DOI: 10.1200/JCO.2013.48.6522

7 National Cancer Institute. Cancer Therapy Evaluation Program. Common Toxicity Criteria (CTC). [version 2.0]. 1999. Available at: https://ctep.cancer.gov/protocolDevelopment/electronic_ applications/docs/ctcmanual_v4_10-4-99.pdf

8 Lund B, Asberg A, Heyman M, Kanerva J, Harila-Saari A, Hasle $\mathrm{H}$, Soderhall S, Jonsson OG, Lydersen S, Schmiegelow K, Nordic Society of Paediatric H and Oncology: Risk factors for treatment related mortality in childhood acute lymphoblastic leukaemia. Pediatr Blood Cancer 56(4): 551-559, 2011. PMID: 21298739. DOI: $10.1002 / \mathrm{pbc} .22719$

9 Li MJ, Chang HH, Yang YL, Lu MY, Shao PL, Fu CM, Chou AK, Liu YL, Lin KH, Huang LM, Lin DT and Jou ST: Infectious complications in children with acute lymphoblastic leukemia treated with the taiwan pediatric oncology group protocol: A 16-year tertiary single-institution experience. Pediatr Blood Cancer 64(10), 2017. PMID: 28371256. DOI: 10.1002/ pbc. 26535

10 Denton CC, Rawlins YA, Oberley MJ, Bhojwani D and Orgel E: Predictors of hepatotoxicity and pancreatitis in children and adolescents with acute lymphoblastic leukemia treated according to contemporary regimens. Pediatr Blood Cancer 65(3), 2018. PMID: 29218844. DOI: $10.1002 / p b c .26891$

11 Canbolat Ayhan A, Timur C and Kalaycik O: A retrospective analysis of complications observed in children with acute lymphoblastic leukemia during chemotherapy. Minerva Pediatr 69(2): 95-105, 2017. PMID: 26200521. DOI: 10.23736/S00264946.16.04239-0

12 Inaba H, Pei D, Wolf J, Howard SC, Hayden RT, Go M, Varechtchouk O, Hahn T, Buaboonnam J, Metzger ML, Rubnitz JE, Ribeiro RC, Sandlund JT, Jeha S, Cheng C, Evans WE, Relling MV and Pui CH: Infection-related complications during treatment for childhood acute lymphoblastic leukemia. Ann Oncol 28(2): 386-392, 2017. PMID: 28426102. DOI: 10.1093/ annonc/mdw557
13 Baytan B, Evim MS, Guler S, Gunes AM and Okan M: Acute central nervous system complications in pediatric acute lymphoblastic leukemia. Pediatr Neurol 53(4): 312-318, 2015. PMID: 26202590. DOI: 10.1016/j.pediatrneurol.2015.03.006

14 Nazir HF, AlFutaisi A, Zacharia M, Elshinawy M, Mevada ST, Alrawas A, Khater D, Jaju D and Wali Y: Vincristine-induced neuropathy in pediatric patients with acute lymphoblastic leukemia in oman: Frequent autonomic and more severe cranial nerve involvement. Pediatr Blood Cancer 64(12), 2017. PMID: 28623857. DOI: $10.1002 /$ pbc.26677

15 Biddeci G, Bosco G, Varotto E, Corradin M, Geranio G, Tridello G, Pillon M, Carraro E, Garetto G, Assadi R, Gigante C and Putti MC: Osteonecrosis in children and adolescents with acute lymphoblastic leukemia: Early diagnosis and new treatment strategies. Anticancer Res 39(3): 1259-1266, 2019. PMID: 30842156. DOI: 10.21873 /anticanres.13236

16 Conter V, Bartram CR, Valsecchi MG, Schrauder A, PanzerGrumayer R, Moricke A, Arico M, Zimmermann M, Mann G, De Rossi G, Stanulla M, Locatelli F, Basso G, Niggli F, Barisone E, Henze G, Ludwig WD, Haas OA, Cazzaniga G, Koehler R, Silvestri D, Bradtke J, Parasole R, Beier R, van Dongen JJ, Biondi A and Schrappe M: Molecular response to treatment redefines all prognostic factors in children and adolescents with b-cell precursor acute lymphoblastic leukemia: Results in 3184 patients of the aieop-bfm all 2000 study. Blood 115(16): 32063214, 2010. PMID: 20154213. DOI: 10.1182/blood-2009-10248146
Received February 23, 2019

Revised April 12, 2019

Accepted April 15, 2019 